\title{
Development of a software tool for the analysis and verification of emergency operating procedures through the integrated simulation of plant and operators actions
}

\author{
A. Expósito , C. Queral , J. Hortal , A. Quiroga , A. Ibarra , J.E. Hulsund , \\ I. González , G. Jiménez
}

Department of Energy Systems, Technical University of Madrid, C/Rios Rosas 21, 28003 Madrid, Spain

\begin{abstract}
Probabilistic safety assessment (PSA) includes operator actions as elements in the set of the considered protection performances during accident sequences. Nevertheless, its impact throughout a sequence is not usually analyzed dynamically. In this sense, it is convenient to make a more detailed analysis about its importance in the dynamics of the sequences, allowing for sensitivity studies with respect to human reliability and response times. For this reason, new developments in simulation software must be able to incorporate operator actions in conventional thermalhydraulic simulations. In this paper, we present one of these new tools, the TRETA/TIZONA-COPMA III coupled codes, which can be used for evaluating the impact in the final plant state of the execution by operators of procedures and the evaluation of the available times for the manual actions of the operators. This software tool consists of a closed-loop plant/operator simulator: a thermalhydraulic code for simulating the plant transient (TRETA for PWR NPPs and TIZONA for BWR NPPs) and the procedures processor (COPMA III) to simulate the operator actions requested by the procedures, both coupled by a data communication system which allows the information exchange (SWBus). The first pilot cases have been performed in order to analyze sequences initiated by secondary side breaks leading to loss of heat sink sequences in a PWR plant. These tests have been carried out using the real plant EOPs for COPMA-III and a PWR plant model for TRETA code. The results of these simulations are presented in this paper.
\end{abstract}

\section{Introduction}

Operator actions play an important role for the most part of accident sequences, although design analyses summarized in safety analysis reports seldom include the consideration of operator actions. Operators are required by compulsory emergency operating procedures (EOP) to perform some checks and actions from the very beginning of an accident. On the other side, probabilistic safety analysis (PSA) includes situations going beyond the design assumptions of automatic protection, and they also include operator actions as important contributors to the plant protection. Nevertheless, the dynamic effects of these actions on the process evolution are not usually analyzed in detail. In most cases, the safety verification studies lack an adequate consideration of operator actions, especially 
regarding how they may enhance the automatic actions or get into conflict with them.

In the framework of this issue, simulation-based human reliability analysis (HRA) methods seem to provide a new direction for the development of advanced methodologies to study the operator action effects during accident sequences (see for example Schryver, 1988; Chandrasekaran et al., 1991; Cacciabue et al., 1992; Cacciabue, 1997; Jakubowski and Beraha (1996); Mosleh and Chang, 2004; Lee and Seong (2004)). Regarding these approaches, the simulation model for the performance assessment of nuclear power plants (NPP) operators is essential, implying the necessity to use simulation codes which include such effects in plant accident sequence simulations.

In the Spanish Nuclear Safety Council (CSN) there is a working group which has developed a simulation-based methodology, named the integrated safety assessment (ISA), considering these new methods. A key aspect of this approach is the automatic generation of dynamic event trees stemming from an initiating event, based on an efficient technique to simulate all branches while taking into account different factors which may affect the dynamic plant behavior in each sequence. This methodology is supported by a unifying theory which combines elements of traditional deterministic and probabilistic analyses.

With regard to the consideration of the operator in the safety analysis, the development of new transient analysis methodologies integrating the operator actions and considering human factors began at the 1990s, after the evaluation of the existing human factors methodologies and the proposal of its improvement, establishing the origin of the second generation HRA methodologies (Swain, 1990; Dougherty, 1990; Lydell, 1992; Bley et al., 1992). Additionally, there was a common opinion that design and validation of procedures require to use better tools for their accomplishment (Hirschberg, 2004). Since 20 years ago, different tools are being developed to cover these needs. Most of them show some common characteristics that can be summarized as:

- They are based on cognitive theory, taking into account errors related to decision making, situation assessment and other cognitive processes.

- EOP computerization is based on task analysis (goals and means) or direct translation, considering or not considering stochastic parameters during its simulation (execution time, EoC/EoO, ...).

- Operator actions are integrated as boundary conditions in the input deck of usual plant simulators, or using dynamic approaches, based on different forms of simulation (CDETs, DDETs, ...).

During the last years, the simulation of operator actions within the ISA methodology has been performed in several ways using different nature approaches, which are presented and described in detail in this paper.

\section{ISA methodology}

New analysis methodologies can be developed based on the possibility of using a simulator driver that is able to generate tree-structured simulation sequences. These techniques, when combined with suitable methods for fault tree quantification, allow for the application of risk-oriented methodologies for various purposes, including the evaluation of Emergency Operating Procedures and Severe Accident Management Guides. An example of such a methodology is the ISA, a systematic verification approach which can be considered as an extension of PSA and accident analysis techniques, supported by the simulation system schematically represented in Fig. 1. The classical PSA static event trees are replaced by a generalized dynamic event-tree concept based on the theory of probabilistic dynamics (DDETs) (Devooght et al., 1996). Both components of the risk, damage and likelihood are considered in this approach in a balanced and simultaneous way.

The main steps of this methodology are (Sanchez and Melara, 1996):

(1) Identification of damage variables and definition of risk acceptable regions in a frequency-damage plot.

(2) Initiating event (IE) and initial state selection.

(3) Modeling the deterministic characteristics of the plant (plant dynamics modeling) including crew procedures.



Fig. 1. ISA methodology schematic representation. 
(4) Modeling the stochastic characteristics of the plant (reliability modeling).

(5) Event sequence generation.

(6) Analysis of the results and verification of the risk requirements.

For a theoretical background and an in-depth description of the different modules depicted in Fig. 1 (see Izquierdo and Sánchez, 1994; Hortal and Izquierdo, 1996; Izquierdo et al., 2002; Labeau and Izquierdo $(2005 a, b))$.

\section{Previous experience in the simulation of EOPs}

A first approach of the CSN to consider the human actions in NPP transients, started in 1994, was the hardcoded implementation of the EOPs as modules of TRETA code. This integration of the EOPs in the simulation was named handbook of operating instructions (HOI), resulting on the TRETA-HOI code version.

A full-scale application of TRETA-HOI was the independent verification of the event-tree delineation and computation of the SGTR initiating event of a Spanish PWR plant (Izquierdo and Sánchez, 1994; Sanchez and Melara, 1996). This study was carried out coupling TRETA-HOI with DYLAM for the calculation of DDETs. As a result of this work, a number of inconsistencies were found in the original delineation of the event tree, which were related to EOPs execution when combined with the complex plant dynamics involved and the large number of branches. Also, it was concluded that the critical point is to create a sufficiently flexible EOP model to deal with all possible outcomes of an accident sequence simulation.

Although this project finished with good results, it was concluded that some aspects of the HOI implementation could be improved:

- HOI had some functional limitations. For example, it was assumed that the crew follows the EOP instructions in a sequential way, not allowing parallel execution of different EOPs, as it is expected to occur in real situations.

- The EOP model was hard-coded, so any change of the model structure and parameters required edition of code sources files.

At the same time, and taking into account these drawbacks, a second approach was started to evaluate the viability of the computerization of procedures with COPMAII, since this EOP simulation system allowed the computerization of EOPs in a flexible way, solving the limitations found in previous works. As a result of this new approach, in 1996, another project was initiated by the Department of Energy Systems group (DES), with the objective of developing a combined system relying on TIZONA-MAAP for plant simulations and on COPMA-II for operator action implementation (García and
Queral, 1997). The plant model for the combined tool was set up, including manual control inputs needed for procedure execution. This work concluded that COPMA-II had several difficulties on the procedure computerization process, mainly tied to the procedures computerization language of this system, the Prola language. This issue, and the fact that COPMA-II was a machine dependent code, made this solution unworkable. For example, during the EOP computerization, it was considered necessary to add Prola instructions to code EOP steps related to actions which demanded manipulations over components (pumps, valves, ...) to control physical parameters. Prola is not designed to allow any change in its grammar, so the new functionality added to the COPMA-II kernel could only be achieved with the participation of the COPMA-II developing team, by modifying COPMA-II kernel source files, coded in lisp programming language. In addition, a high workload was necessary to understand the whole system architecture. This drawback has been solved partly in the new COPMA-III system version, which is highly modularized and based on user friendly flexible structures. Also, it is remarkable that after COPMA-II was developed, no support team was in charge of its maintenance and the source code was not available, so any following application would have important difficulties and those requiring software modifications would be unaffordable.

\section{Description of the present approach}

At present, a new approach to develop this tool has been carried out. This work started after the release of the new COPMA-III software version. The simulation programs that compound the simulation package are (Fig. 2)

(1) For the plant simulation the plant transient simulator codes TRETA and TIZONA are used for pressurized and boiling water reactors (PWR/ BWR) NPPs, respectively. These codes have been developed by the CSN including full scope models. The functionality of these thermalhydraulic codes has been expanded, allowing control of the overall information flow with external codes, simulating the TH transient and determining when the operator actions must be considered.

(2) The computerized procedure system is COPMA-III, developed by the OECD-Halden Reactor Project (HRP) and adapted with the contribution of the DES, CSN and HRP teams. It is able to manage an operational procedure database implemented in XML format.

(3) The information exchange between TRETA/TIZONA and COPMA-III is supported by the SWBus communication interface, also developed by HRP.

One of its key aspects is that, independently of its implementation as a part of the ISA methodology, this tool can 


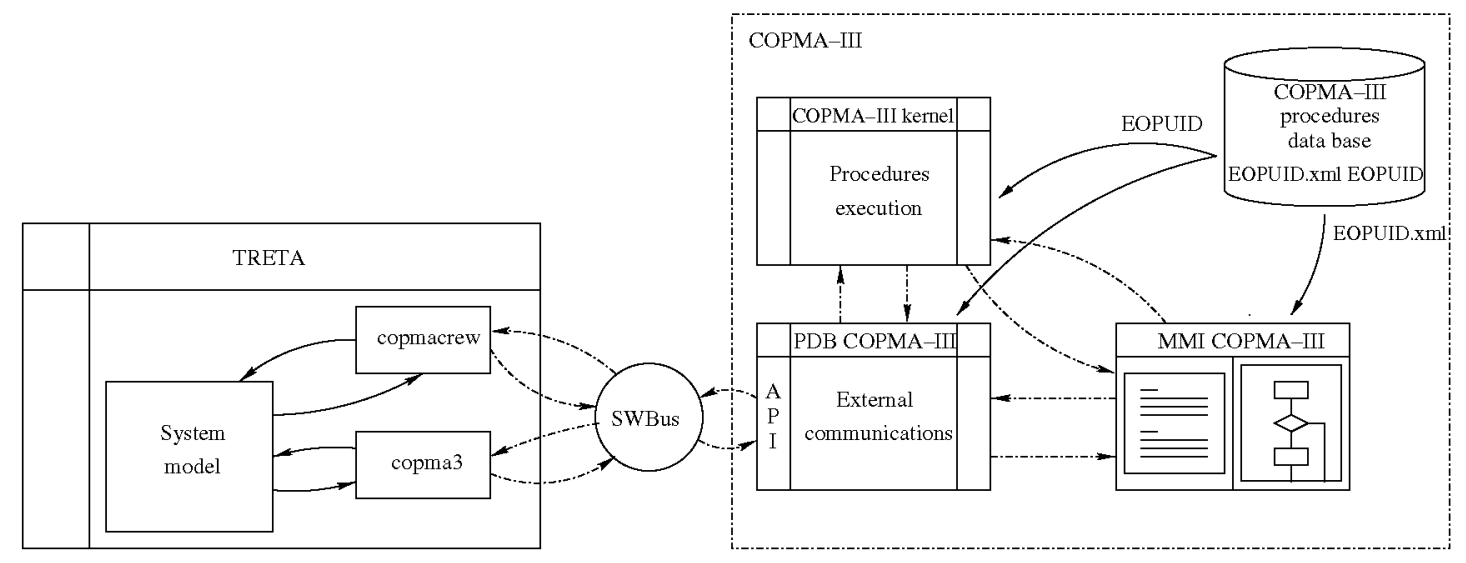

Fig. 2. Schematic representation of the simulation package.

be used as an stand-alone code for a variety of purposes, such as:

- Realistic simulation of level 1 PSA sequences.

- Supporting analysis for IPE and level 2 PSA.

- Design and verification of operating procedures, including Severe Accident Guides.

- Analysis of normal, abnormal and emergency scenarios in order to derive criteria for operator training or evaluation activities.

For the shake of comparison, we can highlight, among the nowadays more developed support tools, the ADSIDAC and the MDET-Crew module (Mosleh and Chang, 2004; Kloos and Peschke, 2007). ADS-IDAC is a tool based on DDET simulation which has a cognitive model (IDAC) to simulate most of the cognitive aspects considered in the current HRA methodologies and the forthcoming second generation ones, for instance EoC, situation assessment and decision making. The plant dynamics are simulated using a RELAP5 in-house adapted version. MDET tool is a combination of Monte Carlo and DDET simulations taking into account operator actions in the simulation via a specific module, named Crew module. This module has a set of operator actuations (EOPs computerized steps) characterized with stochastic execution times and PSF, both calculated in execution time. In both tools, the EOP model is an abstraction using goals and means task analysis.

As previously described, ISA is a methodology with similar characteristics, also based on DDET simulation. Regarding the human actions simulation, TRETA/COPMA-III coupled system presents a EOPs model with a variable detail level, which can range from a high abstraction degree up to individual instruction modeling, always using similar lexical elements than hardcopy procedures. There are similar tools, for example: EOPAS (Jakubowski and Beraha, 1996), ATOPS (Lee and Seong, 2004) and SCOOPE/SIPA (Chatry and Poizat, 1999); but they are not oriented to be applied on PSA studies, just as it is the case of the ISA methodology.
TRETA/COPMA-III tool, within the framework of the ISA methodology, presents similar capabilities than MDET-Crew module. The stochastic parameters considered in the simulations will be the time needed for task execution, calculated taking into account different distribution functions, and the Human Error Probability (HEP), both calculated on running time. COPMA-III/TRETA system does not include a cognitive operator model in its present design. This means that cognitive errors, as EoC/EoO, could be taken into account during the EOP model computerization in a deterministic way. One of the most important advantages of this approach, compared with the other developments, is its highly modular implementation. This characteristic will allow for using TRETA/COPMA-III as a stand-alone tool to perform deterministic simulations.

In the next sections, the different elements of the TRETA/COPMA-III package are described in detail, enumerating their advantages from previous approaches.

\subsection{TRETA and TIZONA codes}

TRETA and TIZONA are modular simulation systems that are able to simulate virtually all the plant systems, including control, protection and balance of plant, and both include the necessary models to simulate PWR and BWR plants, respectively (Izquierdo et al., 2007). The thermalhydraulic modules are based on elaborated models that combine a good representation of most of single and twophase water regimes with a relatively fast solution algorithm. The implementation requirements respond to the following specifications:

- The code is not oriented to one specific type of application.

- The simulation problems are defined by the user in terms of a block diagram topology. A block is a minimal unit of process that computes time dependent output signals as functions of the input signals. The block diagram topology is defined by the interconnections between blocks, i.e. the outputs to inputs linkage. 
- Capability to perform tree-structured simulation, including event-tree automatic generation.

- Capability to incorporate other single-application oriented codes (i.e. RELAP5, MAAP, CONTAIN, ...) as modules using parallel computing techniques.

- Capability to parallelize the calculations, if the problem admits a parallel algorithm solution.

- Capability to admit different user-controlled numerical schemes, from explicit to fully implicit.

The system has been provided with specific routines that constitute open connections of the code, in such a way that other simulation programs may be integrated in the simulation of a physical system described by a block diagram. The connection capabilities are of two non-exclusive types, namely, initial conditions supply and boundary conditions exchange. To connect a code to the TRETA and TIZONA systems, certain communication routines must be inserted into it. The code should also have a structure compatible with the defined specifications.

\subsection{COPMA-III code}

COPMA-III is a procedure following system developed at the Halden Reactor Project (Bisio et al., 2000). It has been designed as an operator support system for guiding the execution of operating procedures. COPMA-III is connected to the plant process computer, or to a plant simulator, from which it receives the information needed for procedure execution.

Some of the most important aspects of this procedures simulation system are

- COPMA-III is a JAVA-based program, resulting on a more flexible system that its predecessor, COPMA-II. The communications library, process data base (PDB) and the system kernel are highly modularized, allowing to add new functionality for communications and procedures simulation for specific applications. It is also possible to create rules for procedures management and execution as needed, making this system suitable for any reactor technology and procedure format (two-column or flow chart). It is even not restricted to NPP procedures.

- New XPA (XML Processing for Antlr) structures and the new system kernel allow to create new instructions with different functions if it is needed, resulting in better EOPs modeling than with Prola language (COPMA-II). Both of them, XPA structures and system kernel, are designed to achieve at least the same semantic complexity than in paper procedures, if desired.

- XPA structures allow to change any simulation parameter of the model without interfering in other parts of the simulation system and models. This is an advantage compared with HOI EOP model. Also, new parameters, managed by COPMA-III system or external codes can be included in the procedure model, so it is possible, for example, to calculate execution times for each instruction taking into account plant and crew condition (workload, stress, ...), updating them at run time.

- The representation of the XPA procedure is made by XML structures. Comparing with Prola (COMPA-II), XPA procedures provide a high degree of flexibility on the computerization process and a wide configuration capability on their visualization.

- COPMA-III can handle the execution of several procedures in parallel, or even several instances of the same procedure. The activity concept, defined as an instance of a procedure that is currently being executed, supports this capability. This means that the system kernel manages procedures in the same way that control room crew does. This feature, already present in COPMA-II, is an advantage with respect to HOI.

Although COPMA-III is much more suitable for EOP computerization, some efforts have been done to maintain some interesting features of COPMA-II. In particular, a set of translation tools has been developed to allow the conversion of Prola procedures to XPA-XML structures (Fig. 3). The interest in this translation capability arose from the existence of an important set of computerized procedures in this coding language. In addition, Prola procedures have some advantages for their maintenance, as compared to the new COPMA-III system. For example, the Prola language has a visual editor with useful tools (automatic flowchart diagram generation, logic condition visual builder, ...), making the procedure coding more user-friendly. Besides, plain ASCII Prola files are human readable, allowing direct visual inspection, checking and modification.

\subsection{COPMA-III and TRETA/TIZONA communications}

In its first release, COPMA-III software package was designed to be used in an interactive way via a manmachine interface based on HTML (Fig. 4). This means that any demand, condition evaluation or component manipulation, can be shown in the HTML interface and evaluated and executed by a user in real time.

However, COPMA-III can be used as a true procedure simulation system since this interface is a computer process that runs independently of the COPMA-III kernel and communicates with it. All of the operator interventions are received by the kernel as function calls resulting in instruction execution, information generation, etc. Due to this, COPMA-III can be used as an unattended simulator allowing automatic simulation via the module copma3 implemented in TRETA/TIZONA, which automatically generates the same function calls that the user would if using the MMI interface (Fig. 2).

The adopted solution to connect COPMA-III and the CSN simulators TRETA/TIZONA has been to use the Software Bus library, SWBus (Quiroga et al., 2006). The SWBus communication interface has been implemented in the COPMA PDB, the COPMA-III module in charge 




Fig. 3. Prola to XML/XPA translator architecture.


Fig. 4. COPMA-III man-machine interface.

of the communications between the COPMA kernel and external codes, and the TRETA module responsible for communicating with COPMA-III, named copma3. The definition of the necessary functionality for the communication has been developed and tested. For this purpose, the different functions implemented in the copma 3 module are

- INITIALIZE_SESSION: It opens a new session with the COPMA system.

- SPWRF_WRAPPER: Sets values of variables of the COPMA kernel. The variables can have numeric as well as symbolic values (e.g. 1 or 'OPEN').

- OPEN OPERATOR SUBSCRIPTION: This function subscribes the COPMA variables to be used by TRETA/TIZONA. Only the subscribed variables will be inspected, see PROC VAR UPDATES. Subscribed variables within the session are returned only if their values have been changed since the last call to PROC VAR UPDATES or GET EVALUATIONS AND VALUES.

- TERMINATE SESSION: This function closes a session opened by INITIALIZE_SESSION.
- SWITCH TO_ACTIVITY: This function changes the current activity to some other running in the current session.

- CREATE ACTIVITY: This function creates a new activity in the current session to run the specified procedure.

- GET INSTRUCTION DETAILS: This function is used to obtain details about the current instruction, for instance the execution time in seconds of the current instruction or the percentage of the maximum work load $100 \%$ - to be allocated by the operation team when the instruction was executed.

- EXECUTE_CURRENT_INSTRUCTION: This function is used to execute the current instruction and to obtain the label of the next instruction.

- GET_EVALUATIONS_AND_VALUES: This function is used to check the status of monitors and update them according to the conditions that they survey. Also, this function gives information about the activities that are in a waiting state, and the conditions of the waits are checked. Finally, this function returns the updated values of the variables previously subscribed with OPEN_OPERATOR_SUBSCRIPTION. 
- END_ACTIVITY: This function finishes an activity started by CREATE_ACTIVITY.

The communications testing was done by means of several test procedures, which had the objective of performing a full range evaluation of the tool communications functionality (Figs. 5 and 6).

\section{Plant and procedures models}

The new combined system needs the definition of the following elements:

- A plant model for the TRETA/TIZONA codes, which must have the necessary interfaces to simulate the manual actions on the required plant systems or components.

- A procedures model with the most relevant steps of the real procedures, allowing it to simulate the scenario considered.

Both of them are described in the following sections.

\subsection{Plant model}

The first stage of the work has been oriented towards the simulation of PWR plant transients, and the thermalhydraulic code TRETA has been used for this purpose. It can simulate all kinds of plant systems including detailed automatic control. Besides, TRETA sends to COPMA-III information about the process variables needed to follow applicable operating procedures. COPMA-III, in turn, sends to TRETA the requests for operator actions derived from the procedures. Manual controls have been included in the plant model, being able to receive the action requests from COPMA-III. TRETA is designed to manage which parts of the simulation have to be computed by each code at every moment. When a manual action request is received from COPMA-III, TRETA addresses it to the right destination. The capability for manual operation is not limited in TRETA, allowing the user to build as many manual controls as desired. The CSN has two plant models available for TRETA, namely Ascó and José Cabrera, which have been verified with several transients. The DES group has finished the verification of a generic PWR-W NPP model (Expósito and Queral, 2003), which has been used for the first pilot cases. This model is composed of the following parts (Fig. 7):

- Vessel model.

- Two-loop reactor coolant system model.

- Reactor cooling pumps model.

- Pressurizer model.

- Secondary side model based on two steam lines.

The two-loop RCS model considers TH behavior similarities between the two loops without pressurizer to simulate the TH transient in NPP with three loops (Spanish PWR NPPs have a RCS with three cooling loops).

The modeled engineered safeguards are the pressurizer and steam generators (SGs) relief and safety valves, steam and feedline isolation, safety injection and auxiliary feedwater (AFW) systems. Additionally, the possibility of failure of one or more of these systems or their main

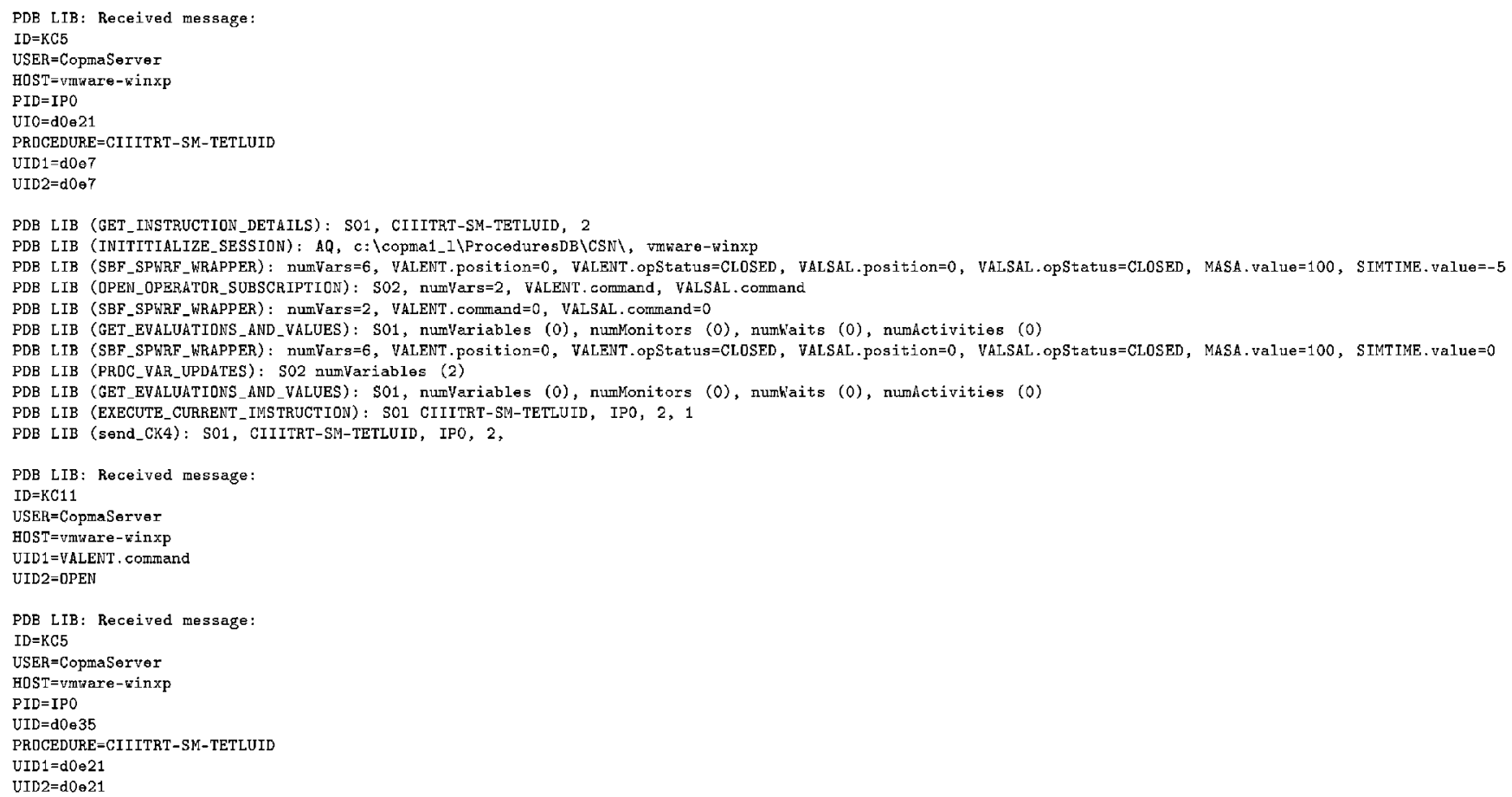


components has been considered. The protection system model includes the automatic protection signals, including the capability of interaction with the operator. In parallel with the development of the PWR model, the DES group performed the Cofrentes NPP model for TIZONA code (Expósito et al., 2005). At this moment, the model has been validated and it is going to be used in the following simulations of BWR plant transients.

\subsection{EOPs simulation}

It can be remarked that there is a tight connection between the semantics of the procedure language and the current functionality implemented in COPMA-III using XML semantics. In order to achieve this, the following instructions have been defined:

- ACTION: Specifies an action/component manipulation to be performed on a component.

- AUTOCHECK: Specifies a process condition to be automatically evaluated based on process variable values. A GOSUB, GOTO or INITIATE instruction may be executed depending on the truth-value of the process condition.

- INITIATE: Creates an activity on a procedure.

- FINISH: Terminates an activity.

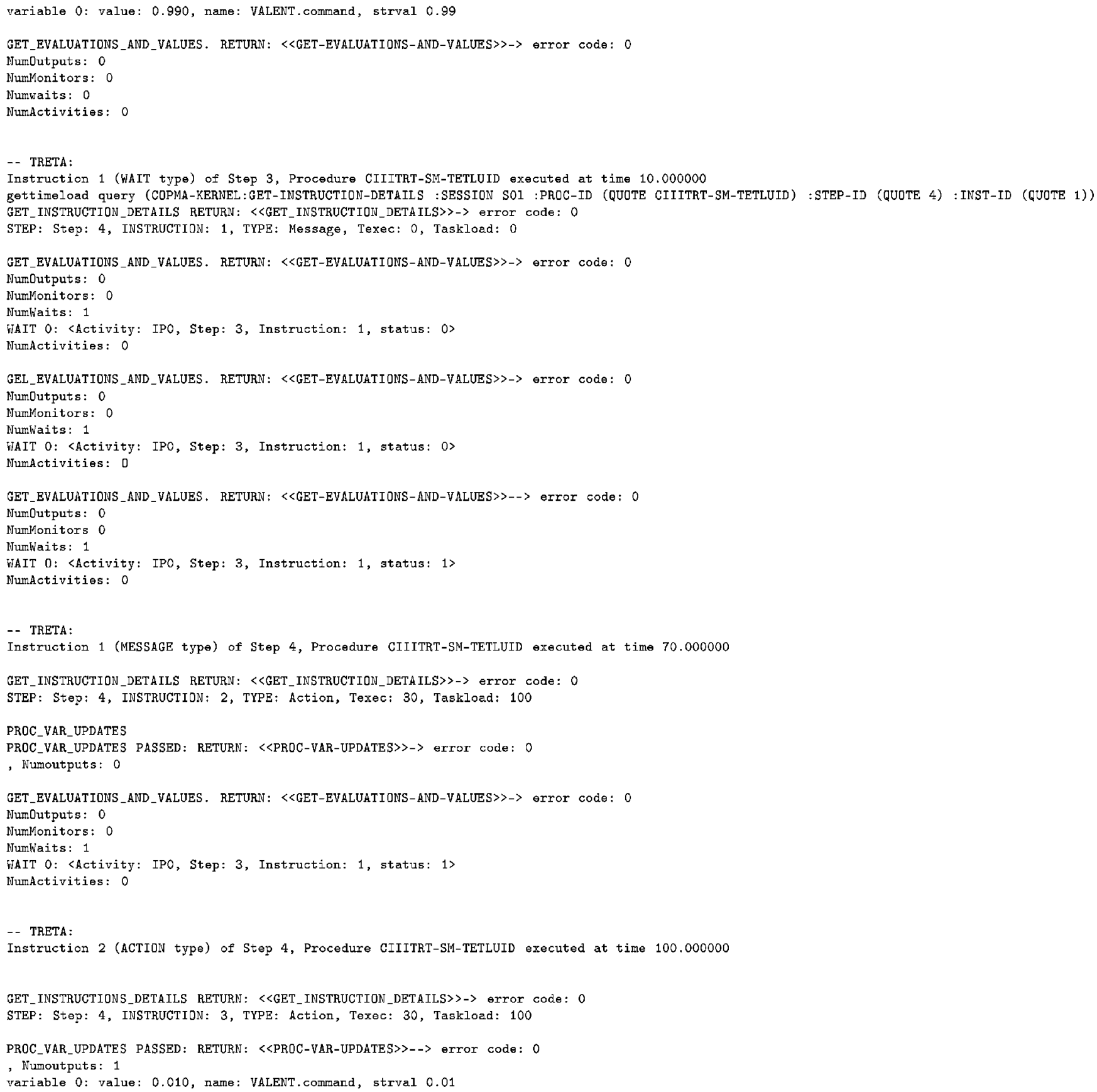

Fig. 6. Debugging information displayed by TRETA. 


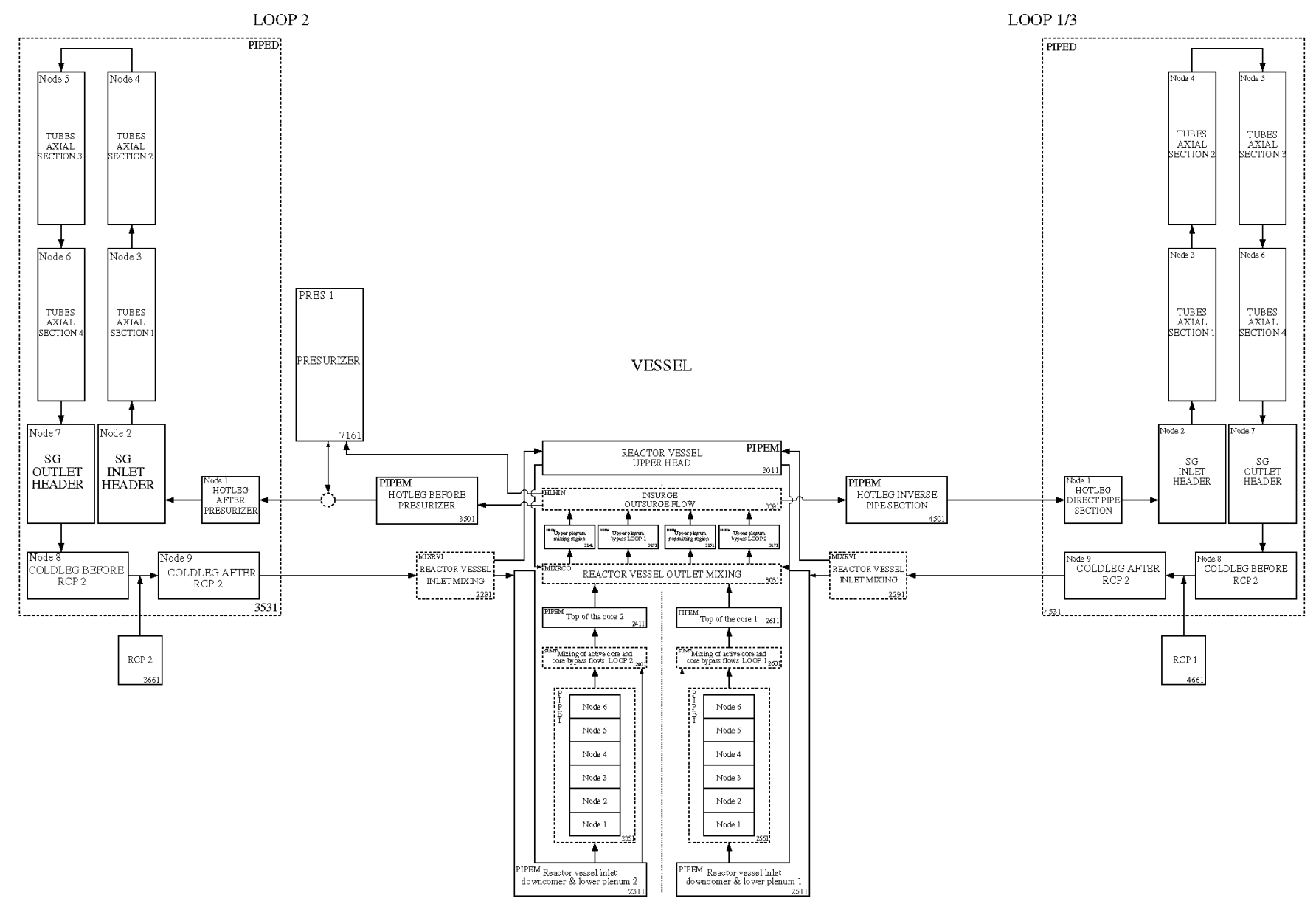

Fig. 7. Scheme of a PWR RCS model for TRETA code.

- GOSUB: Causes the control flow to jump to a specified instruction in the procedure. The first following RETURN instruction will let the flow of control return to the first instruction following the last executed GOSUB.

- GOTO: Causes the flow of control to jump to a specified instruction with no implicit link to a following RETURN instruction.
- MONITOR: Similar to AUTOCHECK but the condition is monitored within a specified time interval.

- RETURN: Causes the flow of control to return to the first instruction following the last executed, nonreturned GOSUB instruction.

- WAIT: Prevents the execution of the next instruction until the indicated time interval expires or the specified process condition is met.

Table 1

Memory structure for the valve component

\begin{tabular}{|c|c|c|c|}
\hline \multicolumn{4}{|c|}{ Valves (valvecomponent) } \\
\hline Management & Attribute & Value & Comment \\
\hline \multirow[t]{2}{*}{ TRETA/TIZONA } & position & Numeric value & Valve opening \\
\hline & autoStatus & AUTO, MAN & Valve operating mode \\
\hline \multirow[t]{2}{*}{ COPMA-III } & command & Numeric value & When the procedure demands an action on the valve \\
\hline & autoSwitch & ON, OFF & \\
\hline User & openval & Constant numeric value & Constant value set by user \\
\hline
\end{tabular}


This set of instructions is enough for procedures computerization, and its functionality has been tested during the computerization of the Westinghouse (PWR) and General Electric (BWR/6) EOPs, and it could be improved if necessary.

With regard to EOPs, a review of the previous experience in this kind of simulation was performed and, in a second stage, a generic methodology was selected to perform the procedure computerization (Queral et al., 2003). This methodology establishes:
- Guidelines for computerizing the different elements present in EOPs:

- Action steps: distinguishing among steps which demand logic or numerical validations (logic or numerical statements) on the plant components/systems state or physical variables (AUTOCHECK), continuous monitoring of physical variables or plant components/systems state (MONITOR), specific actuation demand on plant components/systems (ACTION) and transitions to other procedures or

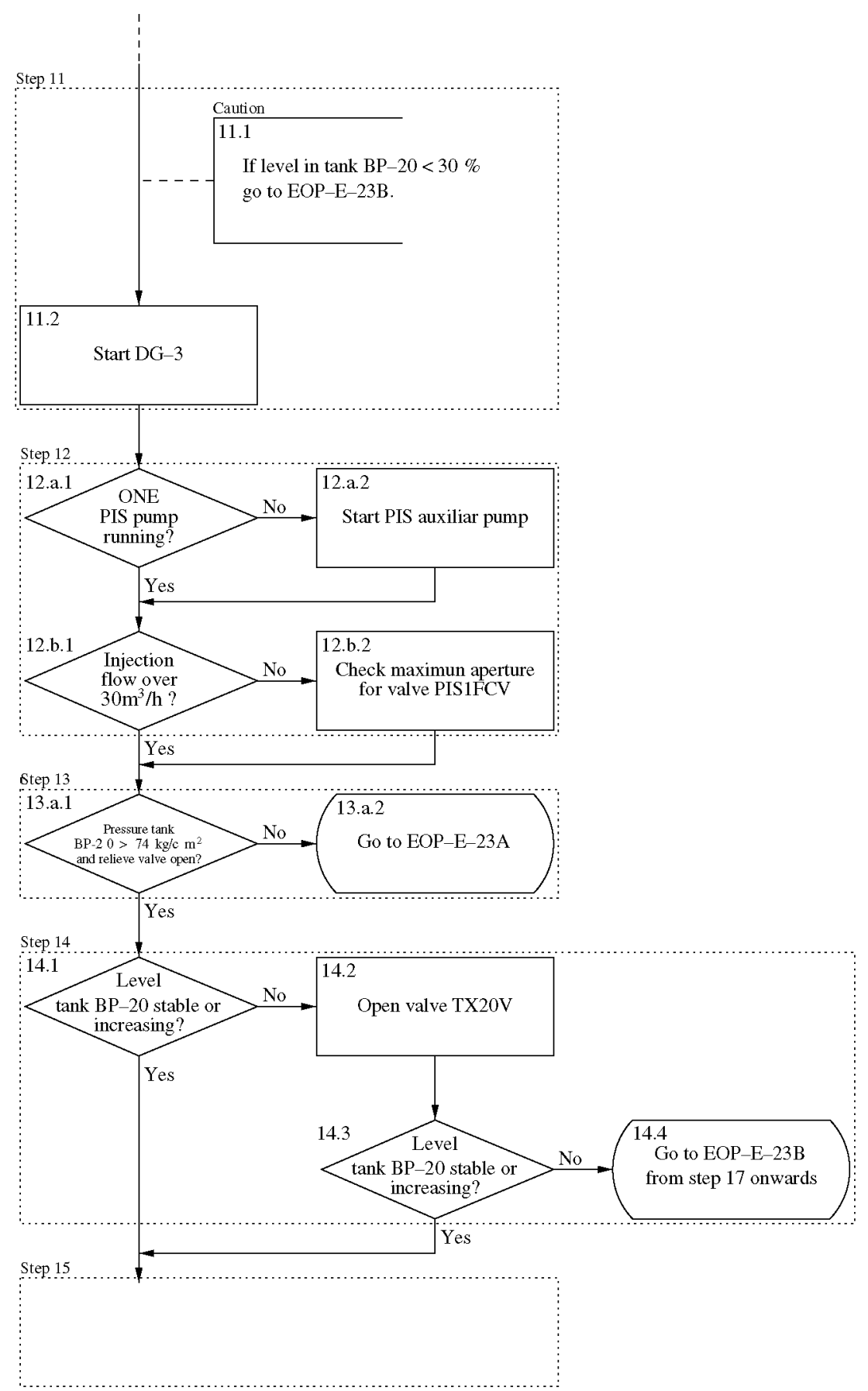

Fig. 8. EOP computerization example: task flow diagram. 
guides (INITIATE). Also, it establishes the required functionality to model immediate action steps, continuous steps, evaluation of physical variables time evolution during the transient and steps implying control actions during a time interval.

- Cautions and notes: providing rules to computerize them as actions steps (specific or continuous) or special operational modes for plant systems or components under punctual conditions.

- Foldout page: establishes the computerization of the actions informed on it as continuous monitoring steps which are applicable at any step in the procedure or procedure series. The most important of these actions are procedure transitions which allow immediate response to new symptoms as they appear.

- FRGs status trees: defines the computerization of these trees as logic statements based on a set of AUTOCHECK instructions checked each minute using a WAIT instruction. This short checking time period is used due to FRGs status trees are monitored by the safety parameters display system (SDPD), and automatic monitoring system supervised by the operators.

- Defines the memory structures and their attributes to manage information related to physical model parameters and components/systems status:

Types of components: valves and pumps (e.g. Table 1).

- System operation modes.

- Physical variables.

- Additionally, the methodology establishes the steps to computerize procedures in a proper manner:

(1) It specifies the modeling detail level for plant systems and components.

(2) It clarifies the plant physical parameters which are important to execute the procedures.

(3) It guides in the computerization of actions over components (pumps/valves), to control physical parameters within a range.

By way of illustration, a simple procedure has been computerized using this methodology. The first task consists of obtaining a task flow diagram from the procedure, considering the procedure instructions of interest for the simulation (Fig. 8). Next, it is necessary to identify, one by one, each task action verb with a computerized instruction (Table 2) and to define the variables needed to manage the information related with this instructions, identifying plant systems, components or physical parameters (Table 3). Finally, the computerization can be carried out, and the obtained computerized procedure should have the same functionality than the hardcopy procedure, as it can be checked by comparing the original task flow diagram with the computerized task diagram (Figs. 8 and 9).
Two important simulation parameters have been implemented for the manual actions demanded by EOPs and computerized in the COPMA-III procedures data base. First one is related with the time required for instruction execution by operators, and it can be obtained from several sources, one of them is the operator training timing in fullscope simulators. For an example about how this data can be extracted from training sessions (see Park et al., 2005; Park and Jung, 2006, 2007). These data are usually averaged for different sequences and operator psychological states and experience skills. An example of a first application of these data source using the COPMA-III/TRETA simulator is provided in the next section. Another data source could be the application of the discrete event simulation (DES) methodology. This methodology is being applied to obtain in a systematic way execution times for unitary operator actions (see for example Yow et al., 2005). The second parameter is related with the workload, psychological and physical, which is assumed by the control room crew during the execution of the simulated instruction. Nowadays, the notion of workload in this context and the objective methods for assessing it are under investigation. One of the most relevant research work in this direction is the one carried out by the KAERI human factor working group. Within the scope of this research, this group is assessing the existing methodologies to quantify workload and complexity of the operator actions demanded by EOPs (Jung et al., 2001; Park et al., 2001, 2004). Both research lines, DES and task load methodologies tested by the KAERI working group, have been

Table 2

Type of steps, defined tasks and computerized instructions related to the example procedure

\begin{tabular}{lll}
\hline Step & Considered subtask & Instruction \\
\hline 11 & 11.1 & MONITOR \\
& 11.2 & ACTION \\
12 & $12 . a .1$ & AUTOCHECK \\
& $12 . a .2$ & ACTION \\
& $12 . b .1$ & AUTOCHECK \\
& $12 . b .2$ & ACTION \\
13 & $13 . \mathrm{a} .1$ & MONITOR with INITIATE \\
14 & 14.1 & AUTOCHECK \\
& 14.2 & ACTION \\
& 14.3 & AUTOCHECK \\
& 14.4 & INITIATE \\
\hline
\end{tabular}

Table 3

Some of the defined tasks, computerized instructions and variables related to the example procedure

\begin{tabular}{llll}
\hline $\begin{array}{l}\text { Considered } \\
\text { subtasks }\end{array}$ & Instruction & Type of variable & Variable name \\
\hline 11.1 & MONITOR & physmagnitude & BP20LEVEL.value \\
11.2 & ACTION & generalvariable & DG3.mode \\
$12 . \mathrm{a} .2$ & ACTION & pumpcomponent & PISPAUX.command \\
14.1 & AUTOCHECK & physmagnitude & BP20LEVEL.tendency \\
\hline
\end{tabular}


considered in the implementation of the TASKEXEC and TASKLOAD parameters, and its future results will be tested and applied when the tool is developed.

\section{Application of the simulation package to the total loss of secondary heat sink}

In this section, the application of the simulation package to procedures simulation is described. First part is dedicated to the methodology developed for the computerization of the EOPs and its application to the sequences that have been simulated. The following section corre- sponds to the simulation of the transients selected as pilot application and the results obtained.

\subsection{Analysis of the EOPs and their computerization}

The sequences selected for checking the tool functionality have been the total loss of secondary heat sink. An indepth study was carried out to define the detail and scope of the procedures model (Expósito and Queral, 2004):

(1) FSAR sequences related to TLFW and SLB were studied.

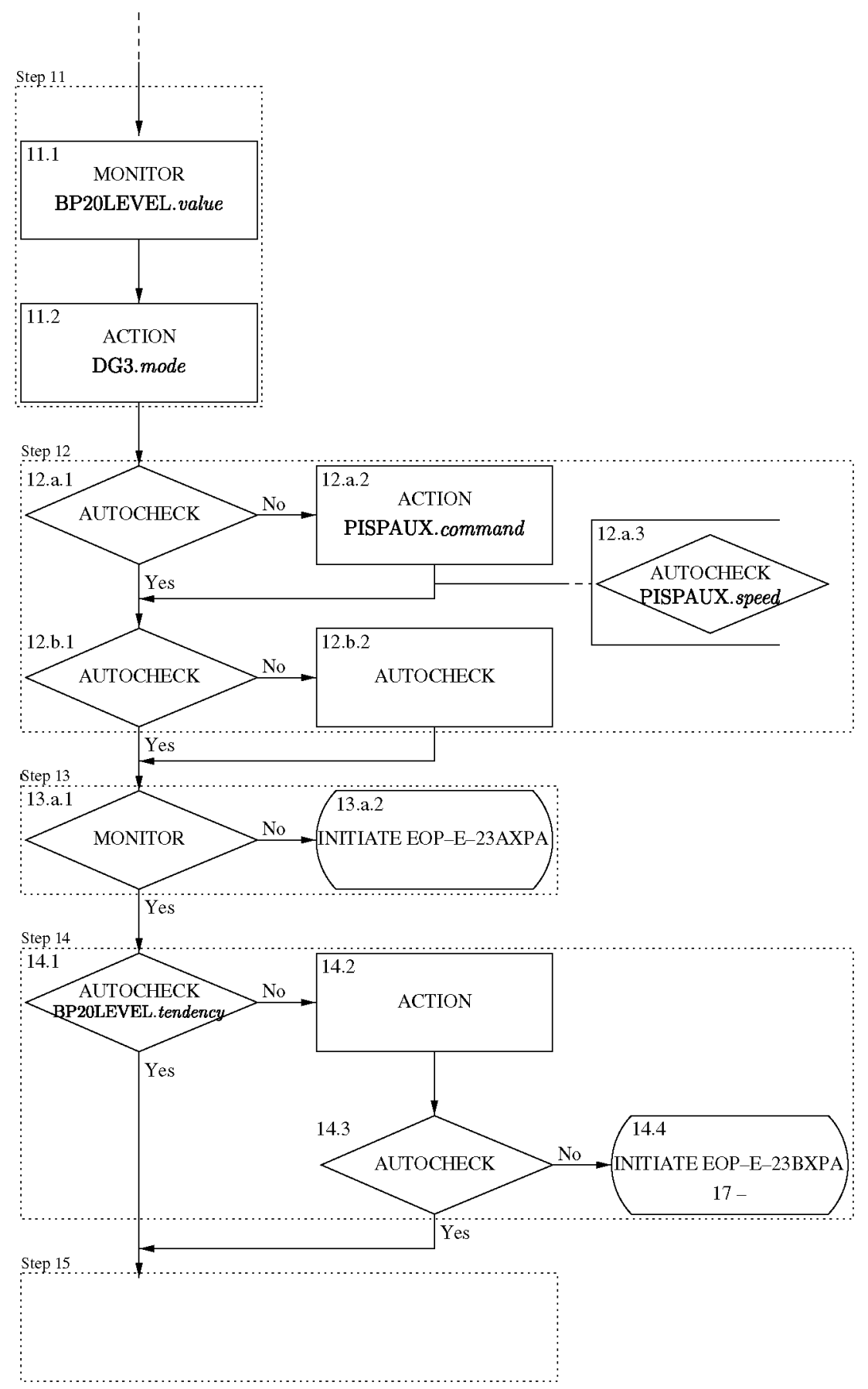

Fig. 9. EOP computerization example: computerized EOP flow diagram. 
(2) PSA studies were analyzed, extracting the information related to human actions considered for these sequences. When possible, EOPs and steps regarding backup and mitigating actions were identified. As a result of this work a simplified event tree for these sequences was depicted (Fig. 10).

(3) These EOPs were revised, seeking for which of them were used in each event-tree sequence, allowing to establish the computerized EOPs model structure. The computerization of the most relevant EOPs related with this kind of sequences was carried out (Expósito et al., 2006): reactor trip (E-0), reactor trip response (ES-0.1), loss of primary or secondary coolant (E-1), response to loss of heat sink (FR-H.1), loss of recirculation capability (ECA-1.1), safety injection (SI), termination (ES-1.1) and transition to SI recirculation (ES-1.3).

(4) Emergency response guidelines basis were revised to clarify the task and goals involved in the actions computerized and to verify that its functionality covered the original designed one.

(5) The final stage of the work was the review of the scientific and technical bibliography about these kind of transients considering technical reports, NUREGs, papers, etc. The objective was to get a detailed knowledge of the plant phenomenology for these sequences, to acquire a general view of the associated problematic and to define the plant physical parameters of interest.

During the computerization process, it was carried out a preliminary testing to check the EOP execution, using manual simulation of operator actions. This task permitted the detection of the need to improve COPMA-III to manage EOP hierarchy (ORG/FRG). In its current version, it is possible to take into account it implicitly, but it is necessary to implement this functionality explicitly in the EOP model attributes.

Also, it has been necessary to interpret some steps of the EOPs, especially those that require operator judgment of the plant conditions, like in manual control of the AFW flow during a loss of feedwater. In this sense, it was concluded that EOP computerization is the most delicate stage of the simulation model development, being necessary the interaction with operators and operators trainers to understand which are the real actuations performed by operators in some situations.

Fig. 10 depicts a generic PSA tree for the total loss of secondary heat sink sequences and the related procedures. The motivations for this selection were that these sequences are well known and that they are complex enough to test the simulation package functionality.

For these sequences, the main objectives specified in EOPs, highly summarized, are (Expósito and Queral, 2004):

- To check and verify the correct actuation of all the systems and safeguards demanded. The actuations performed by the operator to verify and control the AFW flow and the RCS temperature are included in this category.

- To start the feed and bleed cooling procedure in case of loss of secondary heat sink.

These and other less relevant operator actions have been implemented in the COPMA-III computerized procedures (Table 4). All the interfaces needed for these manual actions have been included in the PWR model for TRETA code. The manual controls implemented actuate as required by EOPs and their main objective is to establish

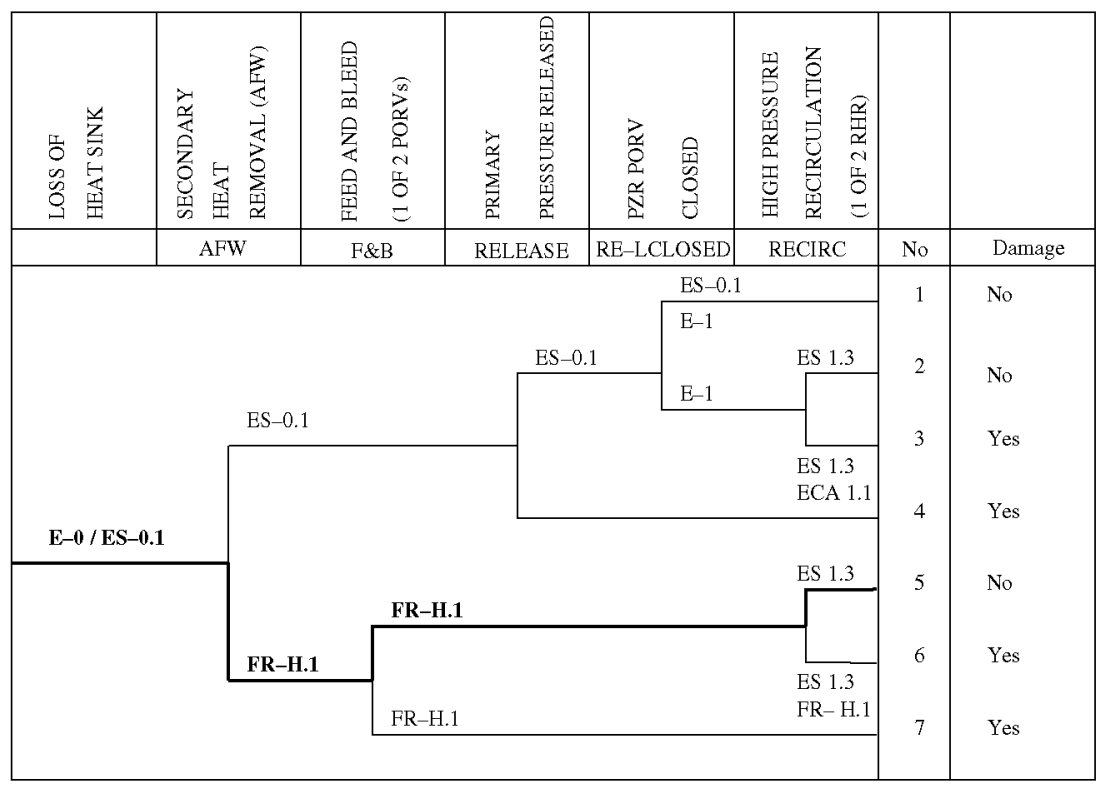

Fig. 10. Total loss of secondary heat sink generic event tree. 
Table 4

Main operator actions implemented in computerized EOPs and plant model for TLFW sequences

\begin{tabular}{lll}
\hline Operator action & EOP-STEP & Code reference \\
\hline Stop RCPs & FR-H.1-3 & A-RCPSTOP \\
RCS depressurization & FR-H.1-6b & A-RCSBLOW \\
Secondary depressurization & FR-H.1-6e & A-SGBLOW \\
Start RCS feed & FR-H.1-9 & A-RCSFEED \\
Start RCS bleed & FR-H.1-12 & A-RCSBLEED \\
\hline
\end{tabular}

Table 5

Averaged time for EOP E-0 execution and event diagnosis time from reactor trip for LSLB, TLFW, LOCA, LOOP, SBO and SGTR sequences (Park et al., 2005)

\begin{tabular}{llrllr}
\hline DBA & \multicolumn{2}{l}{$\begin{array}{l}\text { Performance time of } \\
\text { the diagnosis EOP }\end{array}$} & & \multicolumn{2}{l}{$\begin{array}{l}\text { Diagnosis time from } \\
\text { reactor trip }\end{array}$} \\
\cline { 2 - 3 } & Average $(\mathrm{s})$ & $\sigma(\mathrm{s})$ & & Average $(\mathrm{s})$ & $\sigma(\mathrm{s})$ \\
\hline LSLB & 182.4 & 72.4 & & 412.7 & 128.7 \\
TLFW & 137.2 & 89.8 & & 300.8 & 157.8 \\
LOCA & 135.8 & 47.8 & & 357.5 & 134.9 \\
LOOP & 106.7 & 39.9 & & 271.7 & 79.4 \\
SBO & 101.3 & 55.3 & & 251.7 & 78.6 \\
SGTR & 195.9 & 106.7 & & 403.6 & 199.1 \\
\hline
\end{tabular}

Table 6

Event diagnosis time from reactor trip for LOOP, loss of RHRS, SGTR, LOCA, loss of heat sink and LNFW sequences (Villemeur et al., 1986)

\begin{tabular}{lll}
\hline Initiating event (EOP) & Average & $\sigma$ \\
\hline LOOP (I4B) & $6 \min 50 \mathrm{~s}$ & $7 \min 24 \mathrm{~s}$ \\
Loss of RHRS (IRRA2) & $2 \min 15 \mathrm{~s}$ & $6 \min 45 \mathrm{~s}$ \\
SGTR (A3) & $12 \min$ & $1 \min 24 \mathrm{~s}$ \\
LOCA (A10) & $6 \min 10 \mathrm{~s}$ & $6 \min$ \\
Loss of heat sink (H1.1) & $3 \min 5 \mathrm{~s}$ & $2 \min 5 \mathrm{~s}$ \\
LFW (H2) & $2 \min 50 \mathrm{~s}$ & $1 \min 28 \mathrm{~s}$ \\
Average & $5 \min 32 \mathrm{~s}(332 \mathrm{~s})$ & $3 \min (180 \mathrm{~s})$ \\
\hline
\end{tabular}

Table 7

Task completion time data in coping with TLFW (Park et al., 2005)

\begin{tabular}{lll}
\hline Task & $\begin{array}{l}\text { Time average } \\
\text { (s) }\end{array}$ & $\begin{array}{l}\text { Standard } \\
\text { deviation (s) }\end{array}$ \\
\hline Stoppage of all RCPs & 415.4 & 246.3 \\
Securing the water inventory of SGs & 556.9 & 137.6 \\
Checking criteria for F\&B & 565.6 & 286.4 \\
$\begin{array}{l}\text { Confirming the natural circulation } \\
\quad \text { of RCS }\end{array}$ & 791.6 & 161.8 \\
\hline
\end{tabular}

steady and safe conditions after the correct actuation of protection systems and safeguards. Some of their specifications are:

- A-RCPSTOP: stops RCPS to take advantage of the remaining inventory in the SGs during loss of heat sink sequences.
- A-RCSBLOW: RCS depressurization to establish optimal conditions for initiating RCS feed.

- A-SGBLOW: secondary depressurization for making possible the SGs feed by means of the condensate pumps.

- A-RCSFEED: initiates the RCS feed running two CVCS high pressure pumps.

- A-RCSBLEED: initiates the RCS bleed opening two pressurizer PORVs.

Regarding the executing time implemented for every action computerized in the EOPs model, a preliminary approach was carried out, using data from timing operator
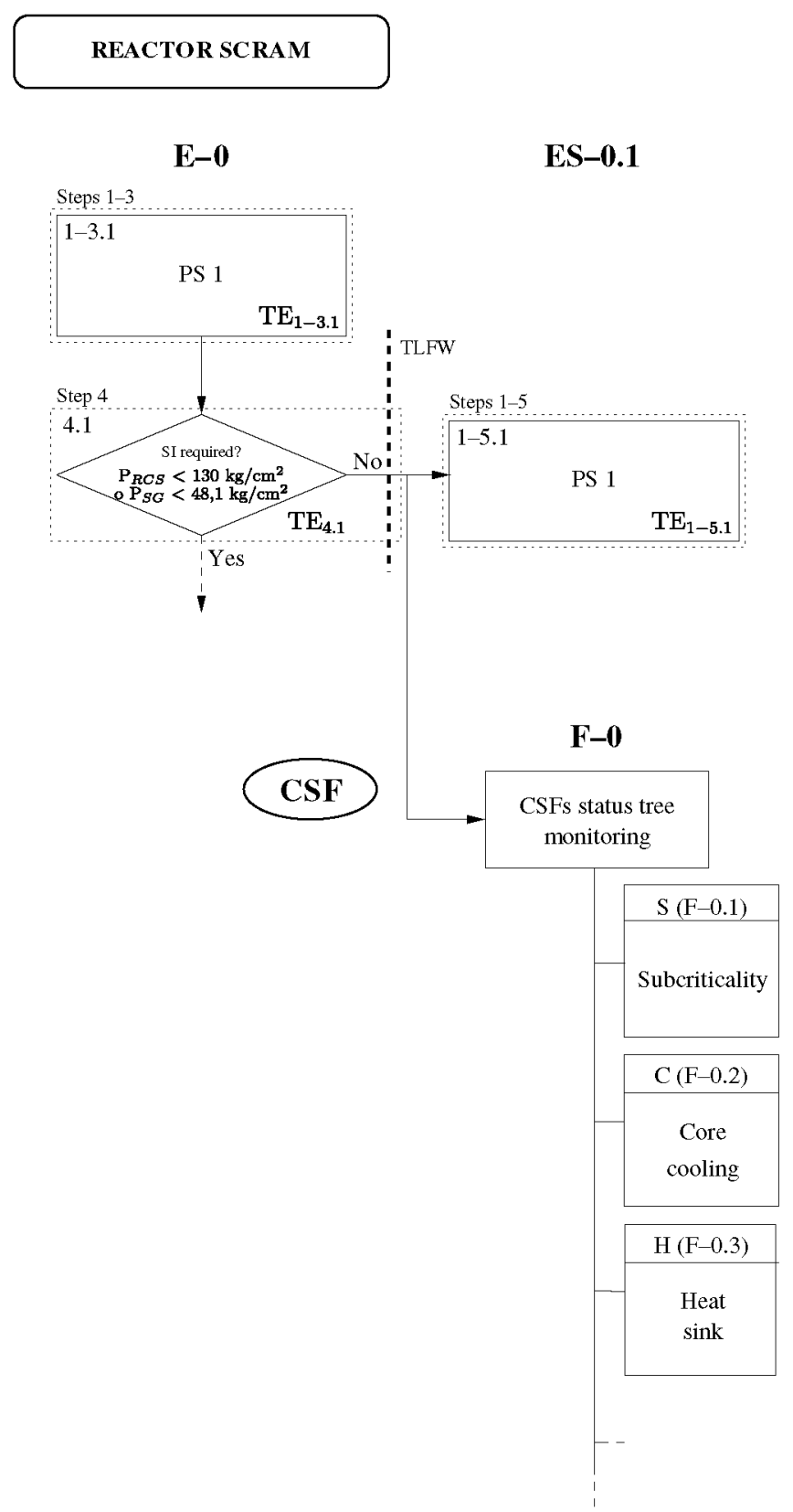

Fig. 11. EOP structure for the loss of total feedwater transient: ORG to CSF monitoring transition. 
training in full-scope simulators (Tables 5-7). The data obtained from Tables 5 and 6 were used to establish the time needed to start E-0 EOP, while the data of Table 7 were used for the different actions computerized in the FRG FR-H.1, described in detail in the next section.

\subsection{Simulation results for the first pilot case: total loss of secondary heat sink}

The initiating event of the transient is a break located at the normal feedwater header at $120 \mathrm{~s}$ (the event sequence is presented in Table 11). This event brings out the loss of normal feedwater, remaining unavailable during the transient. After this moment, the SGs level loss leads to the reactor scram at $149.63 \mathrm{~s}$ (low SG level signal in both SGs) (Fig. 14). This signal involves the AFWS actuation, however, the most important assumption in this simulation is that this safeguard system fails.

The turbine trip is induced by the reactor scram at $149.74 \mathrm{~s}$. Because of the fast SGs depressurization at the beginning of the transient and the unavailability of any feedwater flow source (Figs. 15 and 16), the CSF monitoring tree related with the heat sink is in red condition at $166.4 \mathrm{~s}$ (Fig. 12). That is $48 \mathrm{~s}$ after the reactor scram. This fact would imply the transition to the FRG H.1 at that moment if the control room crew checked the FRG state in the SPDS display. However, in the simulation, this aspect has not been considered, taking into account only the CSF monitoring when it is demanded by the EOPs. This consideration postponed the entry in FRG H.1 in the simulation until $470 \mathrm{~s}$, instead of $166.4 \mathrm{~s}$.

The subsequent evolution of the transient is determined by the manual actions performed by the operator. The most important required by the FRG H.1 are (Table 4, Fig. 13):

- Manual RCPs trip, task (1).

- RCS and secondary depressurization, tasks (2) and (3).

- Feed and bleed criteria monitoring and execution of the maneuver, tasks (4) and (5).

- To establish steady cooling conditions and lower the RCS pressure to values below the LPIS delivery head (these actions are not considered in the current simulations).

The execution of the EOP E- 0 is initiated at $300 \mathrm{~s}, 150 \mathrm{~s}$ after the reactor scram (see Table 8 ) verifying the automatic actuation of the reactor protection system and the core subcritical condition, steps 1-3 (Fig. 11). Afterwards, the EOP ES-0.1 is initiated, reactor trip response, at $410 \mathrm{~s}$. This transition to EOP ES- 0.1 is possible since the RCS and SGs pressures are below 130 and $48.1 \mathrm{~kg} / \mathrm{cm}^{2}$ (Figs. 17 and 18) not considering the SI actuation.

As of this moment, the monitoring of the CSFs status tree $(F-0)$ is initiated simultaneously with the EOP ES-0.1 execution. Considering $60 \mathrm{~s}$ as the time spent in CSF state checking using the SPDS, at $470 \mathrm{~s}$ the ES-0.1 EOP is left, transferring the execution to the FRG H.1, response to the loss of heat sink (Table 9). During this time interval, the strong decrease of the SGs inventories continues due to the actuation of the steam dump bypass (Figs. 15 and 16).

The first operator action demanded by the FRG H.1 is the RCPs stopping at $725 \mathrm{~s}$, step 3 of the procedure (Fig. 13). The RCPs stopping is unconditional, mainly due to the fact that the loss of SG inventory is reduced

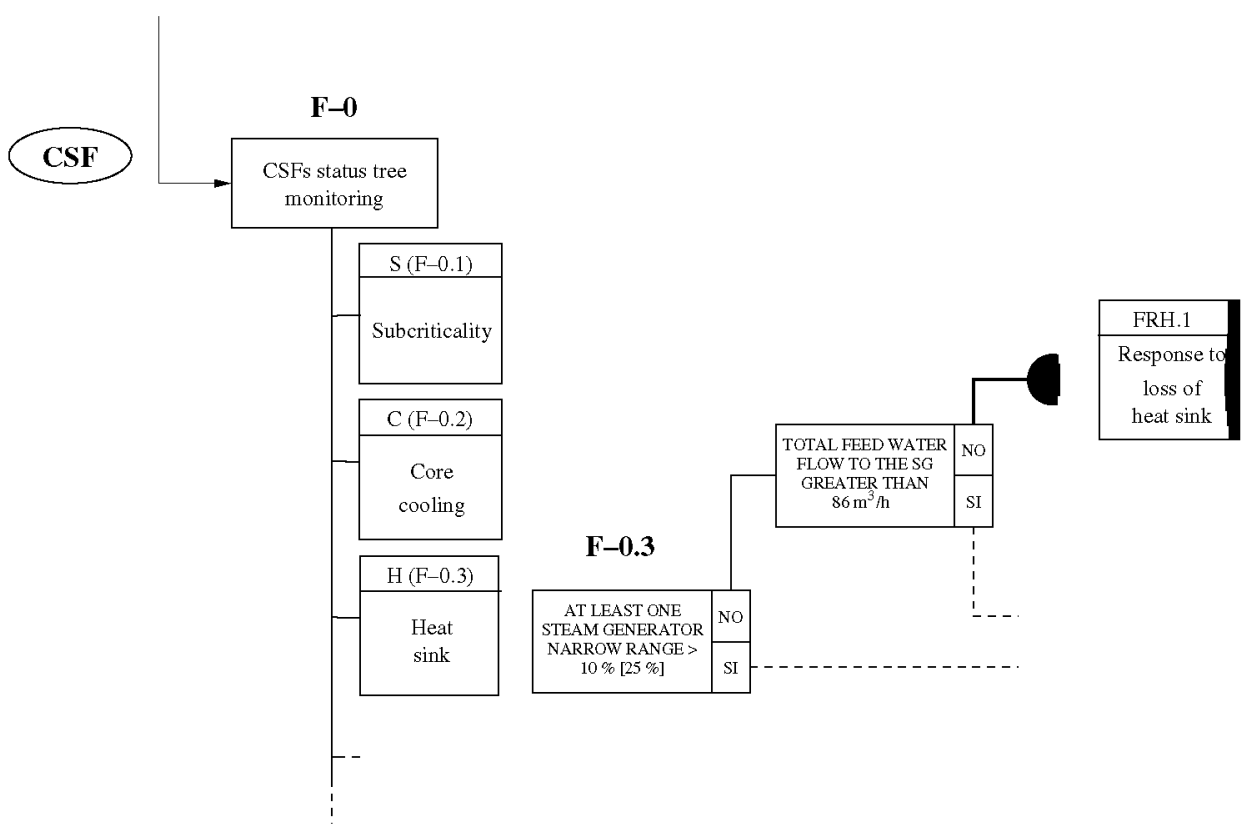

Fig. 12. EOP structure for the loss of total Feedwater transient: CSF monitoring to FRG FR-H.1 transition. 
FR-H.1

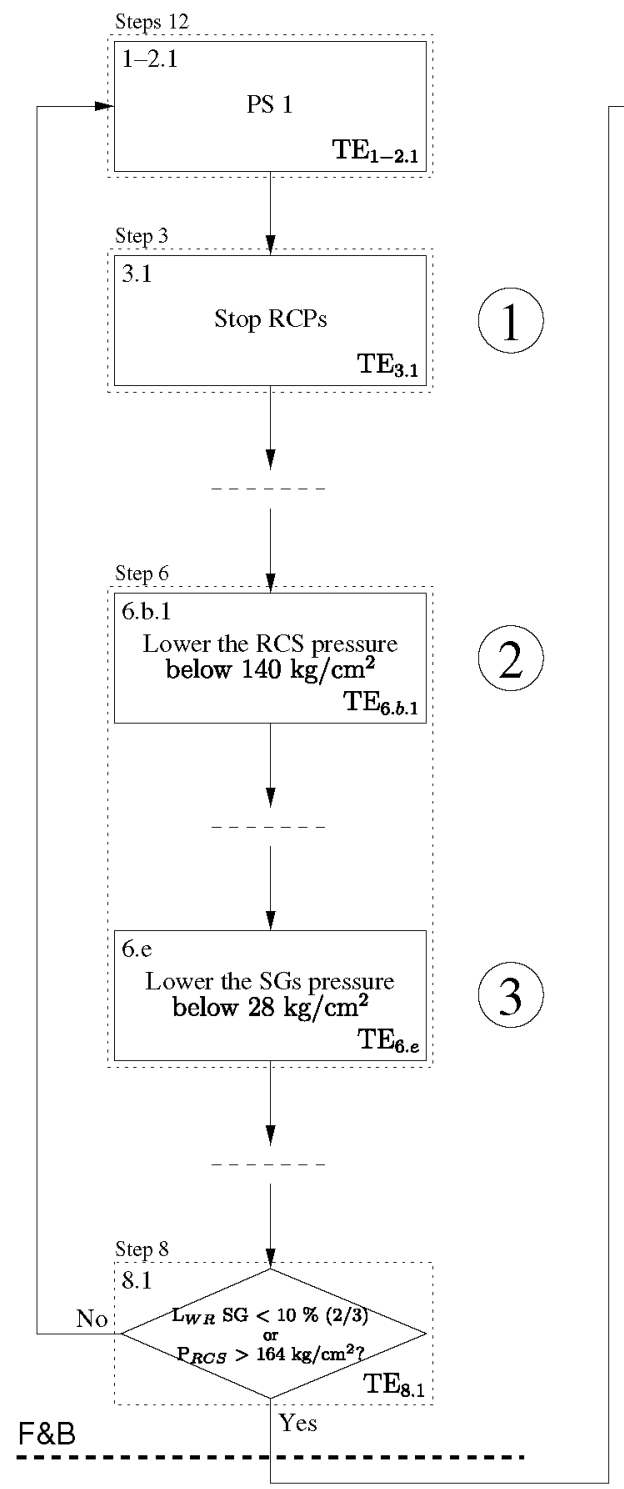

F\&B



Fig. 13. EOP structure for the loss of total feedwater transient: FRG FR-H.1 and F\&B manual actions.

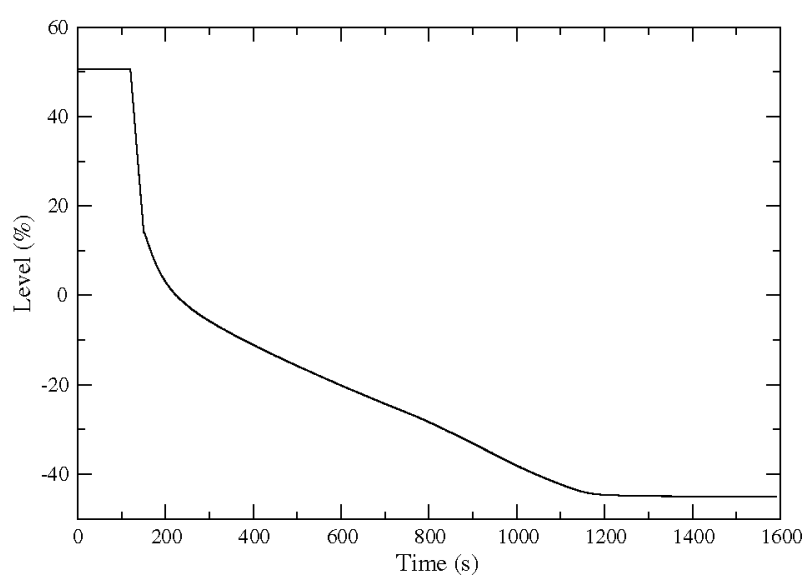

Fig. 14. Total loss of feedwater: SGs narrow range level.
Table 8

Assigned time for EOP E-0 subtasks

\begin{tabular}{lc}
\hline Subtask & TE (s) \\
\hline Entry & 150 \\
$1-3.1$ & 80 \\
4.1 & 30 \\
\hline
\end{tabular}

Table 9

Assigned time for EOP ES-0.1 subtasks

\begin{tabular}{ll}
\hline Subtask & TE (s) \\
\hline Entry & 20 \\
$1-5.1$ & 40 \\
\hline
\end{tabular}




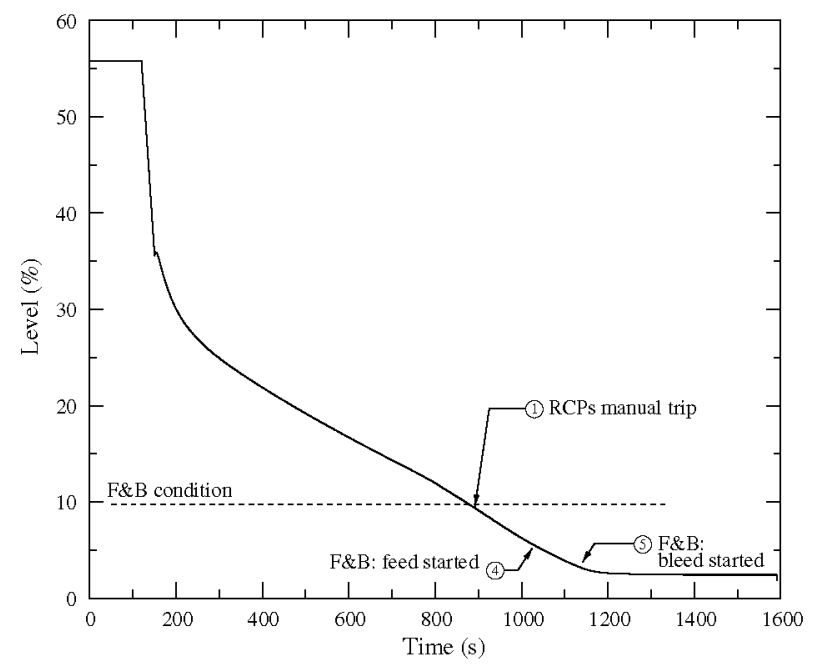

Fig. 15. Total loss of feedwater: SGs wide range level.

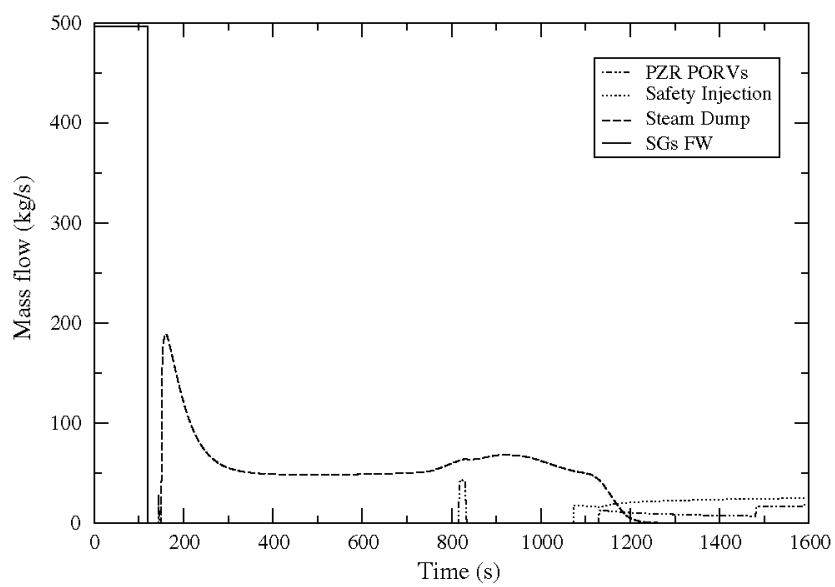

Fig. 16. Total loss of feedwater: total SGs FW, SD, HPSI (manual actuation), and PZR PORVs mass flows.

Table 10

Assigned time for EOP FR-H.1 subtasks

\begin{tabular}{lc}
\hline Subtask & TE (s) \\
\hline Entry & 60 \\
$1-2.1$ & 120 \\
3.1 & 75 \\
$4-6 . a .1$ & 60 \\
6.b.1 & 30 \\
6.c-d.1 & 20 \\
6.e.1 & 30 \\
$7 . a-b .1$ & 50 \\
8.1 & 60 \\
9.1 & 95 \\
$10-11.1$ & 30 \\
12.1 & 30 \\
$13-18.1$ & 300 \\
19.1 & 30 \\
20.1 & 30 \\
\hline
\end{tabular}

in natural circulation and the RCPs coolant heating is avoided, providing more time for SG inventory recovering actions and, therefore, increasing the possi- bilities for avoiding the execution of the $F \& B$ cooling maneuver.

Heat sink recovery actions related with feeding the SGs by means of the condensate system imply the primary and secondary depressurization to 140 and $28 \mathrm{~kg} / \mathrm{cm}^{2}$. These actions, instructions $6 . \mathrm{b}$ y $6 . \mathrm{e}$ of the FR-H.1 procedure, are performed at 815 and $865 \mathrm{~s}$ respectively (Table 10, Figs. 17 and 18). While these actions are performed, the inventory of the SGs is diminishing, reaching the F\&B condition at $870 \mathrm{~s}$ (Fig. 15). Considering that the recovery of the AFWS and the feed by means of the condensate pumps are impossible due to simulation assumptions, the evaluation of this condition is made at $975 \mathrm{~s}$, initiating the feed to the RCS by means of the SI manual actuation at $1070 \mathrm{~s}$ and the bleeding of the primary at $1130 \mathrm{~s}$, steps 9 and 12 of FR-H.1 (Fig. 16). Finally, the simultaneous actuation of feed and bleed tends to establish steady conditions in RCS pressure and temperature, as shown in Figs. 17 and 19. The final state consists of a dynamic balance of the feed and the bleed depending on the volumes of the income and

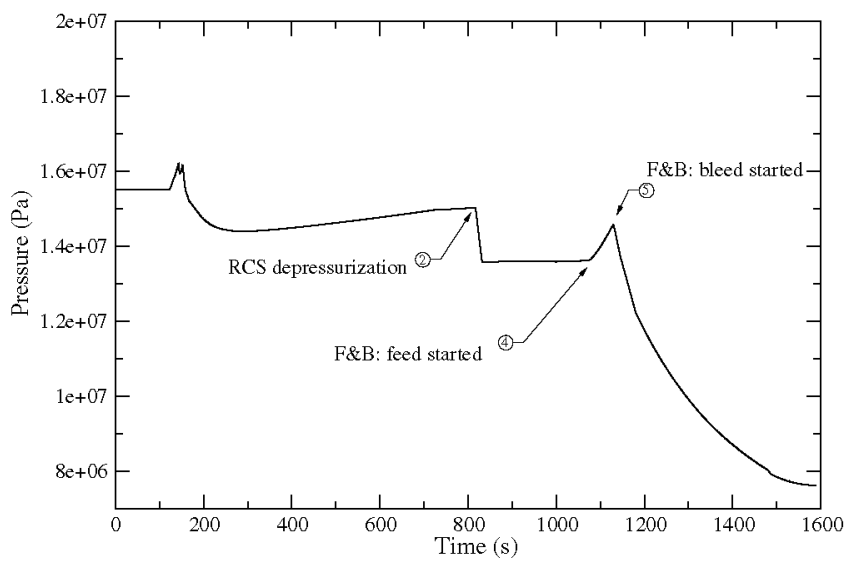

Fig. 17. Total loss of feedwater: RCS pressure.

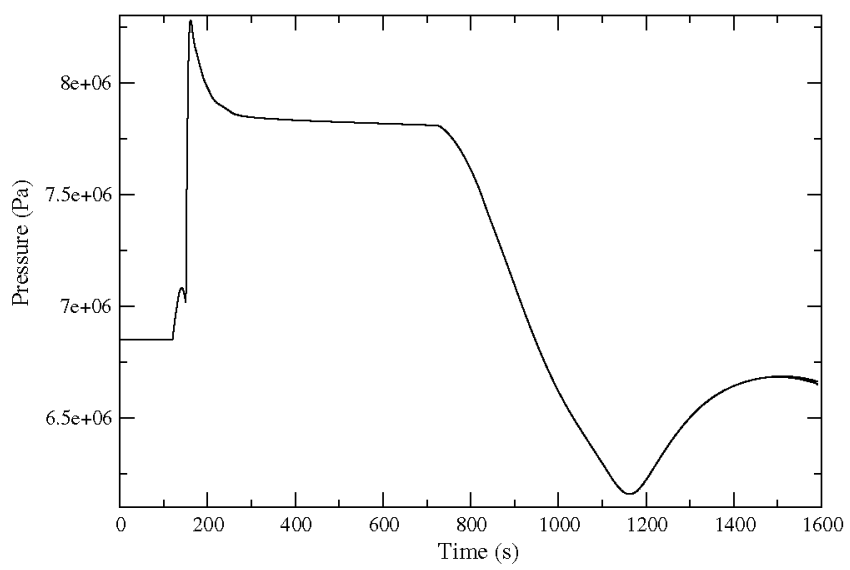

Fig. 18. Total loss of feedwater: SGs pressure. 




Fig. 19. Total loss of feedwater: temperatures in the RCS.

outcome flows, the residual heat and the RCS pressure (Loomis and Cozzuol, 1988).

The pressure is the most important system variable to assess long term cooling with low pressures, as it is required by EOPs to allow LPSI delivery. Several studies have been carried out to establish which is the optimal F\&B procedure for lowering pressure to those values, taking into account different time windows depending on the amount of residual heat (Lanore et al., 1987; Champ and Cornille, 1989) or different configurations for feed and bleed (one/ two HPSI pumps and one/two pressurizer PORVs) (Demuth et al., 1982; Loomis and Cozzuol, 1988). This issue is not considered in our study, finishing the simulation when the feed and bleed flows tend to be steady, regardless of the steady pressure value.

\section{Conclusions}

TRETA/COPMA-III coupled system is capable to perform simulations integrating the effect of operator actions in the nuclear plant state during transient and accidental sequences. This tool is based on a EOPs model with a variable detail level, which can differ from a high abstraction degree to an instruction by instruction computerized EOP version, always using similar lexical elements than hardcopy procedures. TRETA/COPMA-III tool, within the framework of the ISA methodology, presents similar capabilities than other software tools that are currently under development and testing, MDET-Crew module or ADSIDAC. The stochastic parameters considered in the simulations will be the execution time, calculated taking into account different distribution functions, and HEP calculation in execution time. Finally, EoC and EoO can be taken into account as configurable boundary conditions in the EOPs model. One of its key aspects, and an advantage compared with the other developments, is that independently of its implementation as a part of the ISA methodology, this tool can be used as a stand-alone code for evaluating the impact of procedures and guidelines execution by operators in the final state of the plant and the evaluation of the available times for manual actions of the operator in a flexible way.

At this stage of the work, several practical tests have been carried out and all functionality needs defined for the TRETA/COPMA-III tool have been validated. The coupled codes are capable of simulating single sequences with all the requirements of testability and repeatability. When this part of the work is finished, a more ambitious simulation exercise will be undertaken for analysis of the

Table 11

TLFW: manual and automatic actions timing sequence

\begin{tabular}{ll}
\hline Time (s) & Description \\
\hline $\begin{array}{l}\text { Automatic actuations } \\
120\end{array}$ & Main normal feedwater header break (loss of normal feedwater) \\
149.63 & Low SGs level signal. Reactor scram and AFWS actuation demand signals. AFWS failed (total loss of feedwater) \\
149.74 & Turbine trip \\
Manual actionstoperator performance \\
166.4 & Red condition in CSF (SPDS): F-0.3 status tree - FR-H.1 FRG \\
300 & EOP entry (EOP E-0) \\
& Event diagnosis is assumed (TLFW) \\
410 & SI is unnecessary. Task 4.1 \\
& Transitioned to EOP ES-0.1. Task 4.1 \\
470 & CSF status tree monitoring initiated. \\
725 & Transitioned to FRG FR-H.1. Task 1-5.1 \\
815 & Manual RCPs trip (A-RCPSTOP). Task 3.1 \\
865 & RCS depressurization (A-RCSBLOW). Task 6.b.1 \\
870 & Secondary depressurization (A-SGBLOW). Task 6.e.1 \\
975 & F\&B condition becomes true \\
1070.15 & F\&B entry condition is evaluated. Task 8.1 \\
1130 & F\&B maneuver: RCS feed initiated (A-RCSFEED). Task 9.1 \\
1500 & F\&B maneuver: RCS bleed initiated (A-RCSBLEED). Task 12.1 \\
& Dynamic equilibrium between feed and bleed is reached with core cooling in progress. F\&B success criteria satisfied
\end{tabular}


impact of EOPs execution by operators in the final state of the plant and the evaluation of the available response times for manual actions. Furthermore, more improvements have been considered although the development stage of the software tool is nearly finished.

On the other hand, emergency operating procedures need to be evaluated in a PSA context where multiple sequences starting from the same operating conditions have to be considered. In particular, the simulation codes should be able to communicate with a general driver, known as the simulation scheduler, and to receive some signals from it asking for storing or retrieving a particular simulation spot, or to suspend, finish or restart the simulation of a particular sequence. In its current degree of development, COPMA-III does not include these features yet. It is expected, however, that they will be incorporated in the near future and that the applicability of the combined tool can be extended to the automatic simulation of dynamic event trees, just as it is needed for the final implementation of the tool as a part of the ISA methodology.

\section{Acknowledgements}

This work was supported by CSN. Their support is gratefully acknowledged.

\section{References}

Bisio, R., Hulsund, J.E., Nilsen, S, 2000. Brief Introduction to the COPMA-III Tool. Halden Reactor Project. Institute for Energy Technology. Available Online.

Bley, D., Kaplan, S., Johnson, D., 1992. The strengths and limitations of PSA: where we stand. Reliability Engineering and System Safety 38, 3 26.

Cacciabue, P.C., 1997. A methodology of human factors analysis for systems engineering: theory and applications. IEEE Transactions on Systems, Man and Cybernetics - Part A: Systems and Humans 27 (3), 325-339.

Cacciabue, P.C., Decortis, F., Drozdowicz, B., Masson, M., Nordvik, J.P., 1992. COSIMO: a cognitive simulation model of human decision making and behavior in accident management of complex plants. IEEE Transactions on Systems, Man and Cybernetics 22 (5), 1058 1074.

Champ, M., Cornille, Y, 1989. Evaluation of feed and bleed cooling mode in case of total loss of feedwater on 900 MWe PWR. In: CSNI Specialist Meeting on International Coolant System Depressurization.

Chandrasekaran, B., Bhatnagar, R., Sharma, D.D., 1991. Real-time disturbance control. Communication of the ACM 34 (8), 33-47.

Chatry, J-P., Poizat, F. 1999. A safety breakthrough: EDF computerized emergency operation approach. In: 7th International Conference on Nuclear Engineering, ICONE-7037. ICONE.

Demuth, N.S., Dobranich, D., Heninger, R.J., 1982. Loss of feedwater transients for the zion-1 pressurized water reactor. Technical Report NUREG/CR-2656. Los Alamos National Laboratory.

Devooght, J., Izquierdo, J.M., Melendez, E., 1996. Relationships between probabilistic dynamics and event trees. Reliability Engineering \& System Safety 52, 197-209.

Dougherty, E., 1990. Guest editorial: human reliability analysis - where shouldst thou turn? Reliability Engineering and System Safety 29 (3), $283-300$.
Expósito, A., Queral, C., 2003. Almaraz NPP model for TRETA code. Technical Report DSE-18/2003. Department of Energy Systems of the Technical University of Madrid (in Spanish).

Expósito, A., Queral, C., 2004. Analysis of the secondary breaks sequences. Technical Report DSE-01/2004. Department of Energy Systems of the Technical University of Madrid (in Spanish).

Expósito, A., Queral, C., Carballo, J., 2005. Cofrentes NPP model for TIZONA code. Technical Report DSE-11/2005. Department of Energy Systems of the Technical University of Madrid (in Spanish).

Expósito, A., Queral, C., Quiroga, J.A., Ibarra, A., 2006. PWR EOPs computerization for COPMA-III system by means of the developed tools. Technical Report DSE-32/2006. Department of Energy Systems of the Technical University of Madrid (in Spanish).

García, M.A., Queral, C., 1997. Specific agreement CSN-UPM for the development of evaluation instruments of accident management guides. Technical Report DSE-UPM-97. Spanish Nuclear Safety Council (in Spanish).

Hirschberg, S., 2004. Human reliability analysis in probabilistic safety assessment for nuclear power plants. Technical Opinion Papers 4, CSNI.

Hortal, J., Izquierdo, J.M., 1996. Application of the integrated safety assessment methodology to the protection of electric systems. Reliability Engineering \& System Safety 52, 315-326.

Izquierdo, J.M., Sánchez, M., 1994. Application of the integrated safety assessment methodology to the emergency procedures of a SGTR of a PWR. Reliability Engineering \& System Safety 45 (1-2), 159-173.

Izquierdo, J.M., et al., 2002. An integrated PSA approach to independent regulatory evaluations of nuclear safety assessments of Spanish nuclear power plants. Technical Report 28.2002. Spanish Nuclear Safety Council.

Izquierdo, J.M., Sánchez, M., Hortal, J., Meléndez, E., Herrero, R., Queral, C., Expósito, A., González, I., 2007. TRETA and TIZONA fast running thermal-hydraulic codes. Annals of Nuclear Energy 34 (7), 533-549.

Jakubowski, Z., Beraha, D., 1996. An expert system-based aid for analysis of emergency operating procedures in NPPs. In: Nuclear Society of Slovenia (Ed.), III Regional Meeting: Nuclear Energy in Central Europe. Nuclear Society of Slovenia.

Jung, W.D., Kim, J.W., Ha, J.J., 2001. A study on development of the step complexity measure for emergency operating procedures using entropy concepts. Technical Report KAERI/TR-1794/2001. KAERI.

Kloos, M., Peschke, J., 2007. Consideration of human actions in combination with the probabilistic dynamics method MCDET. In: Conference Record for European Safety and Reliability Conference (ESREL).

Labeau, P.E., Izquierdo, J.M., 2005a. Modeling PSA problems - I: the stimulus-driven theory of probabilistic dynamics. Nuclear Science and Engineering 150, 115-139.

Labeau, P.E., Izquierdo, J.M., 2005b. Modeling PSA problems - II: a cellto-cell transport theory approach. Nuclear Science and Engineering $150,140-154$.

Lanore, J.M., Caron, J.L., Ellia-Hervy, A., L'Henoret, J., 1987. Interaction between thermal-hydraulics, human factors and system analysis for assessing feed and bleed risk benefits. In: International SNS/ENS/ ANS Topical Meeting on Probabilistic Safety Assessment and Risk Management.

Lee, S.J., Seong, P.H., 2004. Development of automated operating procedure system using fuzzy colored petri nets for nuclear power plants. Annals of Nuclear Energy 31, 849-869.

Loomis, G.G., Cozzuol, J.M., 1988. Decay heat removal using feed-andbleed for US pressurized water reactors. Technical Report NUREG/ CR-5072. Idaho National Engineering Laboratory. EGG-2526.

Lydell, B.O.Y., 1992. Human reliability methodology. A discussion of the state of the art. Reliability Engineering and System Safety 36, 15 21.

Mosleh, A., Chang, Y.H., 2004. Model-based human reliability analysis: prospects and requirements. Reliability Engineering and System Safety $83,241-253$. 
Park, J., Jung, W., 2006. The appropriateness of the systematic framework to develop diagnosis procedures of nuclear power plants - an experimental verification. Reliability Engineering and System Safety $91,53-65$.

Park, J., Jung, W., 2007. OPERA - a human performance database under simulated emergencies of nuclear power plants. Reliability Engineering and System Safety 92 (4), 503-519.

Park, J., Jung, W., Jaewhan, K., Jaejoo, H., Yunghwa, S., 2001. The step complexity measure for emergency operating procedures: comparing with simulation data. Reliability Engineering and System Safety 74, 63-74.

Park, J., Kim, J., Jung, W., 2004. Comparing the complexity of procedural steps with the operators' performance observed under stressful conditions. Reliability Engineering and System Safety 83, 79-91.

Park, J., Jung, W., Kim, J., Ha, J., 2005. Analysis of human performance observed under simulated emergencies of nuclear power plants. Technical Report KAERI/TR-2895/2005. KAERI.

Queral, C., Quiroga, J.A., Expósito, A., Ibarra, A., 2003. Methodology and tools used for the computerization of the Almaraz NPP EOPs. Technical Report DSE-12/2003. Department of Energy Systems of the Technical University of Madrid (in Spanish).
Quiroga, J.A., Ibarra, A., Expósito, A., Queral, C., 2006. TRETA/ TIZONA and COPMA-III communication implementation. Technical Report DSE-31/2006. Department of Energy Systems of the Technical University of Madrid (in Spanish).

Sanchez, M., Melara, J., 1996. Extending PSA to accident management: the case of the steam generator tube rupture (STGR). Emergency operating procedures assessment. In: Proceeding of the International Conference on Nuclear Engineering (ICONE), vol. 3. ASME.

Schryver, J.C., 1988. Operator model-based design and evaluation of advanced systems: computational models. In: Conference Record for 1988 IEEE Fourth Conference on Human Factors and Power Plants, pp. 121-127.

Swain, A.D., 1990. Human reliability analysis: need, status, trends, and limitations. Reliability Engineering and System Safety 29, 301-313.

Villemeur, A., Moroni, J.M., Mosneron-Dupin, F., Meslin, T., 1986. A simulator-based evaluation of operators' behavior by Electricite de France. In: Proceedings of the International Topical Meeting on Advanced in Human Factors in Nuclear Power Systems, Knoxville, Tennessee, pp. 374-379.

Yow, A., Walters, B., Plott, B., Laughery, R., Persensky, J., 2005 Predicting nuclear power-plant operator performance using discrete event simulation. Cognition, Technology and Work 7, 25-29. 